Review article

\title{
Aplastic anemia- a quick review
}

\begin{abstract}
Aplastic anemia is a rare bone marrow disorder characterized by pancytopenia. It can be congenital but is usually idiopathic but rarely certain drugs, chemicals and infections can cause aplastic anemia. It is diagnosed with hypocellular bone marrow. The definitive treatment is allogenic hematopoetic stem cell transplant, however supportive care with transfusion and immunosuppressive therapy can provide symptomatic relief and improved quality of life. Patients should always be encouraged to enroll into clinical trials.
\end{abstract}

Volume 7 Issue 5 - 2017

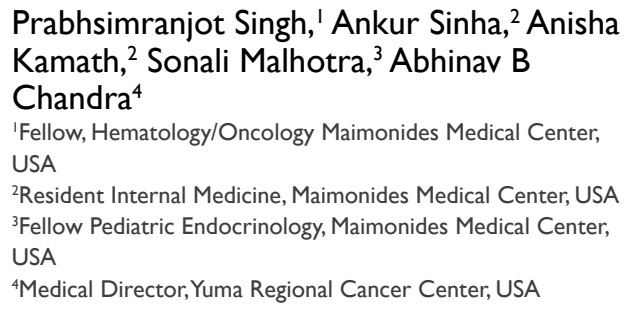

Correspondence: Prabhsimranjot Singh, Fellow of Hematology/Oncology, Maimonides Cancer Center, 6300 Eight Avenue, 2nd Floor, Brooklyn, New York, USA, Tel 7I8-765-2600, Fax 718-765-2630, Email psingh2@maimonidesmed.org

Received: July 31, 2016 | Published: March 12, 2017

\section{Introduction}

Aplastic anemia (AA) is a rare hematologic disease and a distinctive example of bone marrow failure syndromes. AA is characterized by diminished or absent hematopoietic precursors in the bone marrow, most often due to injury to the pluripotent stem cell. The designation "aplastic anemia" is a misnomer, because the disorder is characterized by pancytopenia rather than anemia. The disease is estimated to occur in two to four individuals per million populations every year. ${ }^{1-6}$

Paul Ehrlich introduced the concept of aplastic anemia in 1888 when he studied a case of a pregnant woman who died of bone marrow failure. ${ }^{7}$ However; it was not until 1904 that Anatole Chauffard named this disorder aplastic anemia.

\section{Etiology}

AA results secondary to a reduction in the pluripotent stem cell number below a critical mass. This is due to a conflict between selfrenewal versus differentiation (Figure 1). The ultimate effect is stem cell or bone marrow failure. Usually AA is idiopathic, however it can be attributable to cytotoxic drugs (chloramphenicol, gold) ${ }^{8}$ radiation, toxic chemicals (like Benzene, solvents and glue vapors), viral infections (Epstein- Virus Infection, Seronegative Non A-G hepatitis), ${ }^{9,10}$ immune related disorders (Eosinophilic fasciitis, SLE, Graft versus host disease), ${ }^{11}$ thymoma, anorexia nervosa and paroxysmal nocturnal hemoglobinuria(PNH).

\section{Drug induced AA}

Majority of patients exposed to the implicated drugs do not develop AA, and the exact mechanism for the idiosyncratic reaction is unknown. The P-glycoprotein, Multi-Drug Resistance Gene, (MDR1) gene product, and the multidrug resistance-associated protein, are energy-dependent transmembrane efflux pumps for a variety of lipophilic drugs. ${ }^{12,13}$ They are responsible for keeping the drugs out of the cells (Figure 2). An overexpression of these proteins confers the multidrug resistance phenotype to cancer cells, whereas an underexpression in normal cells allows cytoplasmic accumulation of drugs and enhances their toxic effects. ${ }^{14}$

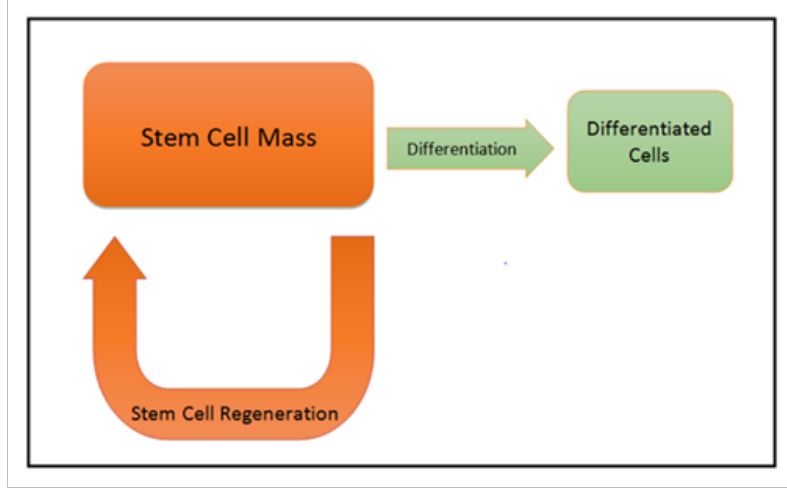

Figure I Depicting the delicate balance between stem cell differentiation and regenration in the etiology of aplastic anemia.

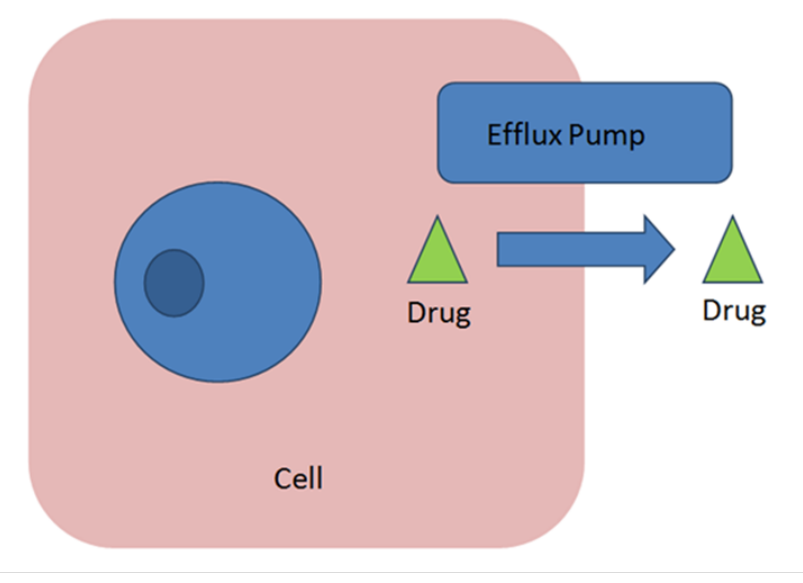

Figure 2 Depicting the mechanism of drug efflux from the cell.

\section{Viral infections}

Certain viruses are implicated in causing aplasia. 


\section{Parvovirus B 19}

This virus more commonly attacks pro-erythroblasts and causes transient red cell aplasia, as seen in patients with chronic hemolytic anemia. However, pancytopenia can also occur, particularly in patients who are immune compromised. ${ }^{15}$

\section{Hepatitis virus and human immunodeficiency virus (HIV)}

These viruses may involve $\mathrm{T}$ cell activation with release of cytokines or activation of a cytotoxic $\mathrm{T}$ cell clones which recognize similar target antigens on both liver and bone marrow cells. ${ }^{16}$

\section{Autoimmune AA}

Autoimmune bone marrow inhibition may be mediated by the release of interferon gamma (IFN-gamma) due to its marrow suppressing effect, under the influence of the transcription factor T-bet and/or cytokines such as TNF-alpha and various interleukins. ${ }^{17}$

Unregulated lymphocyte activation, like mutations of perforin in hemophagocytic lymphohistiocytosis, or an autoimmune state due to impaired numbers or function of cluster of differentiation (CD4+/ $\mathrm{CD} 25+$ )/ transcription factor fork-head box $\mathrm{P} 3$ positive (FOXP3+) T regulatory cells, secondary to the actions of $\mathrm{T}$ helper 17 (Th17) cells results in a hematopoietic inhibitory response. This inhibition may be mediated by IFN-gamma or the cytokine cascade released by IFNgamma ultimately leading to apoptotic death of hematopoietic stem cells in the bone marrow. ${ }^{18-22}$

\section{Clinical manifestations}

Patients with AA are usually well, prior to the diagnosis. AA occasionally comes to medical attention because of fatigue and other symptoms associated with progressive anemia. More common presentations include recurrent infections due to profound neutropenia

Table I Classification of aplastic anemia by severity ${ }^{23}$

\begin{tabular}{|c|c|c|}
\hline Moderate & Severe & Very severe \\
\hline Decreased bone marrow cellularity & Bone Marrow Cellularity $<30 \%$ & \\
\hline $\begin{array}{l}\text { Depression of at least two of the three } \\
\text { hematopoietic lineages not fulfilling the severity } \\
\text { criteria as specified in the right column. }\end{array}$ & $\begin{array}{l}\text { Depression of at least two of the following } \\
\text { three hematopoietic lineages. } \\
\text { Absolute neutrophil count }<0.5 \times 10^{9} / \mathrm{L} \text {. } \\
\text { Transfusion dependence, with absolute } \\
\text { reticulocyte count }<60 \times 10^{9} / \mathrm{L} \text { or platelet } \\
\text { count }<20 \times 10^{9} / \mathrm{L} \text {. }\end{array}$ & $\begin{array}{l}\text { Patients that fulfill criteria for severe } \\
\text { aplastic anemia but with an absolute } \\
\text { neutrophil count of }<0.2 \times 10^{9} / \mathrm{L} \text {. }\end{array}$ \\
\hline
\end{tabular}

Table 2 Main diagnostic characteristics of aplastic anemia and hypoplastic myelodysplastic syndromes ${ }^{24}$

\begin{tabular}{lll}
\hline Criterion & Aplastic anemia & Hypoplastic MDS \\
\hline $\begin{array}{l}\text { Cytopenia } \\
\text { Bone Marrow Cellularity }\end{array}$ & Present & Present \\
Hematopoiesis & Aplastic (<10\% Cellularity) & Hypocellular \\
Erythropoiesis & Present in nests, or “Hot Spots” & Present \\
Myelopoiesis & Typically decreased & Present \\
Megakaryopoiesis & Decreased or absent & Present \\
Erythropoiesis & Possible & Possible \\
Myelopoiesis & Normal Morphology & Possible \\
Megakaryopoiesis & Normal Morphology & Possible \\
Blasts & Absent & Variable \\
CD34+ or CDII7+ & Nearly Absent & Normal or increased \\
Marrow Fibrosis & Absent & Possible \\
Karyotype & Clonal abnormality possible (about I2\%) & $-7 /$ del (7q) $-5 /$ del(5q) \\
PNH Clone & Frequent & Unusual \\
Splenomegaly at Diagnosis & Absent & Possible
\end{tabular}

or mucosal hemorrhage due to thrombocytopenia. Infections are typically bacterial. Invasive fungal infection is a common cause of death; especially in subjects with prolonged and severe neutropenia. ${ }^{23}$ Increased menstrual flow is also a common complaint in premenopausal women.

\section{Diagnosis}

Patients with AA, have clinical findings consistent with pancytopenia, especially pallor and petechiae. The liver, spleen or lymph nodes are generally not enlarged. A complete blood count with differential, bone marrow aspiration and biopsy with measurement of red cell membrane or neutrophil CD59 by flow cytometry, and cytogenetics are indicated. ${ }^{24}$ Diagnosis of AA is established by demonstration of pancytopenia and hypocellular bone marrow. ${ }^{25}$ An important differential diagnosis is of hypoplastic myelodysplatsic syndrome (MDS), which should be kept in mind due to significant difference in management and prognosis (Table 2) (Figure 3).

\section{Classification}

Aplastic anemia is classified as moderate, severe (SAA) or very severe aplastic anemia (vSAA) as shown in Table $1 .{ }^{26}$

\section{Management}

Patents with moderate AA are managed with individualized approach considering the symptoms, disease severity, and changes in the degree of cytopenia over time. Close monitoring often is appropriate, especially when symptoms and transfusion requirements are minimal. ${ }^{27}$ SAA or vSAA on the other hand are successfully treated, over 70 percent will die within one year. ${ }^{1}$ Patients should not be subject to initial trials of G-CSF or erythropoietin. ${ }^{28}$ There are various treatment options available however; Immunosuppressive Therapy (IST) remains the most commonly used first line of therapy. Prognosis depends on the severity of aplastic anemia and the age of the patient (Figure 4). 


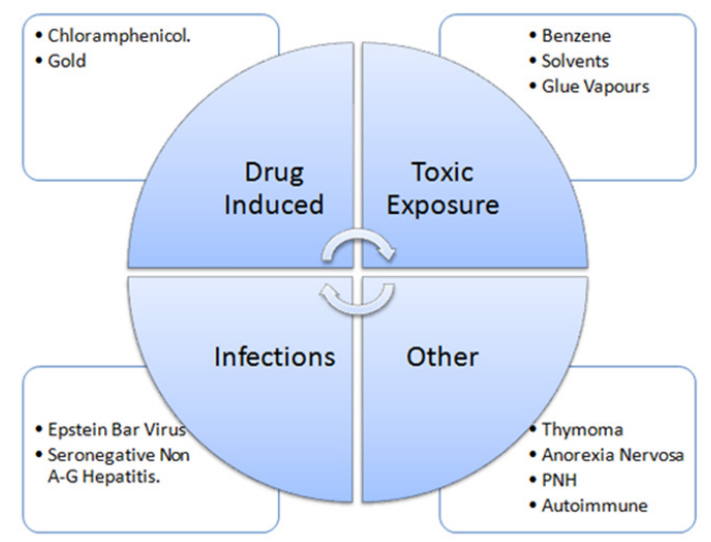

Figure 3 Depicting the various etiologies of the aplastic anemia.

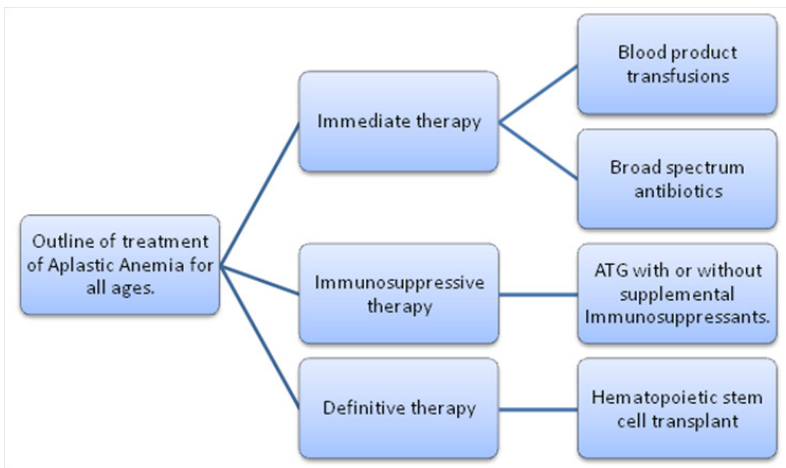

Figure 4 Figure depicting the Outline of treatment of Aplastic Anemia for all ages.

\section{Immediate measures}

The immediate aim is to eliminate symptoms of anemia and thrombocytopenia.

A. PRBC transfusion - no specific cutoff of hemoglobin and hematocrit is available. It is advised to transfuse only if patient is symptomatic from anemia, preferably use leucocyte reduced and irradiated blood. Overuse of blood products should be avoided.

B. Platelet transfusion if the platelet count is less than $10,000 / \mu 1$, or evidence of bleeding.

C. Broad spectrum parenteral antibiotics should be instituted.

\section{Immunosuppressive therapy}

Anti thymocyte globulin (ATG) - ImmunoglobulinG (IgG) against human antigen reactive $\mathrm{T}$ lymphocytes (equine-derived) causes either elimination of $\mathrm{T}$ lymphocytes in peripheral blood or alteration in T-lymphocyte function. In aplastic anemia these $\operatorname{IgG}$ may induce complete or partial hematologic response. It has half-Life of 1.512 days; it should only be prescribed by physicians experienced in immunosuppressive therapy and patients should only receive the drug in facilities equipped and staffed with adequate laboratory and supportive medical resources. It is required to be administered by a double lumen central line and platelet count should be $\geq 20,000 \mathrm{~K} /$ $\mu \mathrm{L}$. Beta-blockers should be held before ATG administration to avoid suppressing physiologic responses to anaphylaxis. It is contraindicated in patients with a history of hypersensitivity to antithymocyte globulin, and other equine gamma globulins. An ATG skin test should be performed for hypersensitivity to horse serum followed by desensitization if reacting to intradermal injection. The treatment should be discontinued if there is evidence of anaphylaxis, unremitting thrombocytopenia, or unremitting leukopenia. Aplastic anemia patients may need prophylactic platelet transfusions. Patients should be observed carefully for previously masked reactions when reducing dose of corticosteroids, and other immunosuppressants. A randomized trial by Scheinberg et al, concluded that rabbit ATG was inferior to horse ATG as the initial treatment of SAA as was reported by the hematological response and survival. ${ }^{29}$

\section{ATG with cyclosporin(CsA)}

A more intensive regimen including ATG and cyclosporine appears to provide superior results compared with treatment with ATG alone in patients with SAA. ${ }^{30} \mathrm{CsA}$ administration is initiated on Day 1 . Starting dose is $10 \mathrm{mg} / \mathrm{kg}$ per day $(15 \mathrm{mg} / \mathrm{kg} /$ day in children). Target trough level is between 200 and $400 \mathrm{ng} / \mathrm{mL}$. For high blood pressure, it is advised to start anti-hypertensives like amlodipine and start azithromycin for bothersome gingival hypertrophy. If renal functioning worsens or creatinine $\geq 2 \mathrm{mg} / \mathrm{mL}$, temporary cessation of CsA therapy and later reintroduction at lower doses with further increases as tolerated is recommended. Antimicrobial prophylaxis for Pneumocystis carinii with monthly aerosolized pentamidine while patient is on therapeutic doses of CsA is recommended. Sulfa drugs are avoided, alternative regimen with Dapsone or Atovaquone are used when Pentamidine cannot be used or in very small children. Antibacterial, antiviral and antifungal prophylaxis is not routinely administered with standard horse ATG/CsA. ${ }^{31}$

\section{Agents added to ATG+CsA}

Addition of agents like GCSF, danazol, mycophenolate mofetil, sirolimus and erythropoetein have been studied in prospective randomized studies with no reported difference in response, relapse, clonal evolution or survival. ${ }^{32-36}$

\section{Other agents}

High dose cyclophosphamide, modified high dose cyclophosphamide plus cyclosporine, anti-IL- 2 receptor antibody, daclizumab IV every other week for a total of five doses, arsenic trioxide plus cyclosporine. ${ }^{37-40}$ Simple definition of hematological response is no longer limited to meeting blood count criteria for SAA, which closely correlates with transfusion independence and long term survival.. Majority ( $90 \%$ ) of the hematological responses occurs within 3 months after ATG. ${ }^{41,42}$

Cyclosporine taper is a common practice but adequate prospective comparative studies of such strategy are lacking. Anecdotal and retrospective reports support taper to decrease the rate of relapse. ${ }^{4,43}$

\section{Hematopoietic stem cell transplantation (HSCT)}

Allogeneic hematopoietic cell transplantation (HCT) is curative, but is limited by the availability of a HLA-matched sibling. ${ }^{44}$ Bone Marrow is the preferred source of stem cells in AA, not peripheral blood, unlike hematological neoplasms. ${ }^{45,46}$ Matched unrelated - donor transplantation should be reserved for patients for whom an initial course of IST has failed especially in children and young adults. ${ }^{47}$

In patients under the age of 20 with SAA or vSAA, with an HLAmatched sibling, treatment with allogeneic HCT over treatment with an immunosuppressive regimen is recommended [48]. In patients 20-50 years of age with SAA or vSAA in otherwise excellent health 
with a fully HLA-matched sibling donor, it is recommended to treat with allogeneic HCT over treatment with an immunosuppressive regimen. For those individuals without a matched sibling donor, immunosuppressive therapy is recommended over the use of matched unrelated, mismatched related, or mismatched unrelated HCT [49]. In patients over 50 years with SAA or vSAA, the use of immunosuppressive therapy over HCT is suggested because of the very high risk of graft-versus- host disease in patients age $\geq 45$ years. ${ }^{50,51}$

\section{Prognosis and survival}

Without treatment patients with aplastic anemia have high mortality rate close to 70 percent within one year. ${ }^{52}$ Usually clinical course is variable with complications due to pancytopenia (infections, bleeding), relapse and clonal evolution however with increasing availability of hematopoetic stem cell transplant and effective immunosuppressive therapy, survival rates have increased to as high as 80 percent. $^{53}$

\section{Conclusion}

The treatment of severe aplastic anemia, whether by allogeneic stem cell transplantation or immunosuppression, has improved dramatically over the years, and long-term survival of more than $75 \%$ of patients can be anticipated with either therapy.

In conclusion, a multidisciplinary approach is recommended to systematize relevant results and develop a treatment plan. Consideration should be given to seeking an expert advice on the diagnosis and management of patients where there is uncertainty, or when an inherited bone marrow failure syndrome is being considered and henceforth an enrollment in clinical trials should be encouraged.

\section{Funding}

None.

\section{Acknowledgements}

None.

\section{Conflicts of interests}

The authors declare that there is no conflict of interest.

\section{References}

1. Young NS, Calado RT, Scheinberg P. Current concepts in the pathophysiology and treatment of aplastic anemia. Blood. 2006;108(8):2509-2519.

2. Marsh JC, Ball SE, Cavenagh J, et al. Guidelines for the diagnosis and management of aplastic anaemia. Br J Haematol. 2009;147(1):43-70.

3. Young NS, Bacigalupo A, Marsh JC. Aplastic anemia: pathophysiology and treatment. Biology of blood and marrow transplantation. J Am Soc Blood Marrow Transplant. 2010;16(1 Suppl):S119-S125.

4. Young NS, Maciejewski JP. Aplastic Anemia in Hoffman Basic Principles and Practice. (5th edn), Churchill Livingston Elsevier, Philadelphia, USA. 2009.

5. Young NS. Acquired aplastic anemia. Ann Intern Med. 2002;136:534.

6. Wallerstein RO, Condit PK, Kasper CK, et al. Statewide study of chloramphenicol therapy and fatal aplastic anemia. JAMA. 1969;208(11):2045.

7. Ehrlich P. Ueber einem Fall von Anämie mit Bemerkungen über regenerative Veränderungen des Knochenmarks. Charité-Annalen. 1888; $13: 300-309$.

8. Doney K, Storb R, Buckner CD, et al. Treatment of gold-induced aplastic anaemia with immunosuppressive therapy. $\mathrm{Br}$ J Haematol, 1988;68(4):469-472.

9. Baranski B, Armstrong G, Truman JT, et al. Epstein-Barr virus in the bone marrow of patients with aplastic anemia. Ann Intern Med. 1988;109(9):695-704.

10. Brown KE, Tisdale J, Barrett AJ, et al. Hepatitis-associated aplastic anemia. N Engl J Med. 1997;336(15):1059-1064.

11. Song Y, Du X, Hao F, et al. Immunosuppressive therapy of cyclosporin A for severe benzene-induced haematopoietic disorders and a 6-month follow-up. Chem Biol Interact. 2010;186(1):96-102.

12. Kay AG. Myelotoxicity of gold. Br Med J. 1976;1(6020):1266.

13. Brodie MJ, Pellock JM. Taming the brain storms: felbamate updated. Lancet. 1955;346(8980):918-919.

14. Calado RT, Garcia AB, Gallo DA, et al. Reduced function of the multidrug resistance $\mathrm{P}-$ glycoprotein in CD34+ cells of patients with aplastic anaemia. Br J Haematol. 118(1): 320.

15. Kurtzman G, Young N. Viruses and bone marrow failure. Baillieres Clin Haematol. 1989;2(1):51.

16. Brown KE, Tisdale J, Barrett AJ, et al. Hepatitis-associated aplastic anemia. N Engl J Med. 1997;336(15):1059.

17. Solomou EE, Keyvanfar K, Young NS. T-bet, a Th1 transcription factor, is up-regulated in T cells from patients with aplastic anemia. Blood. 2006;107(10):3983.

18. Shichishima T1, Okamoto M, Ikeda K, et al. HLA class II haplotype and quantitation of WT1 RNA in Japanese patients with paroxysmal nocturnal hemoglobinuria. Blood. 2002;100(1):22.

19. Saunthararajah Y1, Nakamura R, Nam JM, et al. HLA-DR15 (DR2) is overrepresented in myelodysplastic syndrome and aplastic anemia and predicts a response to immunosuppression in myelodysplastic syndrome. Blood. 2002;100(5):1570-1574.

20. Young NS, Calado RT, Scheinberg P. Current concepts in the pathophysiology and treatment of aplastic anemia. Blood. 2006;108(8):2509-2519.

21. Hoffman R, Young N, Ershler WB, et al. Diffuse fasciitis and aplastic anemia: a report of four cases revealing an unusual association between rheumatologic and hematologic disorders. Medicine (Baltimore). 1982;61(6):373-381.

22. De Masson A, Bouaziz JD, Peffault de Latour R, et al. Severe aplastic anemia associated with eosinophilic fasciitis: report of 4 cases and review of the literature. Medicine (Baltimore). 2013;92(2):69-81.

23. Torres HA, Bodey GP, Rolston KV, et al. Infections in patients with aplastic anemia: experience at a tertiary care cancer center. Cancer. 2003;98(1):86-93

24. Scheinberg $P$, Marte $M$, Nunez $O$, et al. Paroxysmal nocturnal hemoglobinuria clones in severe aplastic anemia patients treated with horse anti-thymocyte globulin plus cyclosporine. Haematologica. 2010;95(7):1075-1080.

25. Rovó A, Tichelli A, Dufour C. Diagnosis of acquired aplastic anemia Bone Marrow Transplant. 2013;48(2):162-167.

26. Rozman C, Marín P, Nomdedeu B, et al. Criteria for severe aplastic anaemia. The Lancet. 1987;330(8565):955-957.

27. Scheinberg P, Young NS. How I treat acquired aplastic anemia. Blood. 2012;120(6):11851196. 
28. Marsh JC, Ganser A, Stadler M. Hematopoietic growth factors in the treatment of acquired bone marrow failure states. Semin Hematol. 2007;44(3):138-147.

29. Scheinberg P, Nunez O, Weinstein B, et al. Horse versus Rabbit Antithymocyte Globulin in Acquired Aplastic Anemia. $N$ Engl J Med. 2011;365(5):430-438.

30. Frickhofen N, Heimpel H, Kaltwasser JP, et al. Antithymocyte globulin with or without cyclosporin A: 11-year follow-up of a randomized trial comparing treatments of aplastic anemia. Blood. 2003;101(4):12361242 .

31. Scheinberg P, Young NS. How I treat acquired aplastic anemia. Blood. 2012;120(6):1185-1196.

32. Kojima S, Hibi S, Kosaka Y, et al. Immunosup-pressive therapy using antithymocyte globulin,cyclosporine, and danazol with or without human. 2000

33. Scheinberg $\mathrm{P}$, Nunez $\mathrm{O}, \mathrm{Wu} \mathrm{C}$, et al. Treat-ment of severe aplastic anaemia with combined immunosuppression: anti-thymocyte globulin, ciclosporin and mycophenolate mofetil. $\mathrm{Br} J$ Haematol. 2006;133(6):606-611.

34. Scheinberg $\mathrm{P}, \mathrm{Wu} \mathrm{CO}$, Nunez $\mathrm{O}$, et al. Treatment of severe aplastic anemia with a combination of horse antithymocyte globulin and cyclosporine, with or without sirolimus: a prospective randomized study. Haematologica. 2009;94(3): 348- 354.

35. Gluckman E, Rokicka Milewska R, Hann I, Nikiforakis E, Tavakoli F, et al. (2002) Results and follow-up of a phase III randomized study of recombinant human-granulocyte stimu-lating factor as support for immunosuppressive therapy in patients with severe aplastic anaemia. $\mathrm{Br}$ J Haematol. 119(4):1075-1082.

36. Teramura M, Kimura A, Iwase S, et al. Treatment of severe aplastic anemia with antithymocyte globulin and cyclosporin A with or without G-CSF in adults: a multicenter randomized study in Ja-pan. Blood. 2007;110(6):1756-1761.

37. Brodsky RA, Chen AR, Dorr D, et al. High-dose cyclophosphamide for severe aplastic anemia: long-term follow-up. Blood. 2010;115(11):2136-2141.

38. Maciejewski JP, Sloand EM, Nunez O, et al. Recombinant humanized anti-IL-2 receptor antibody (daclizumab) produces responses in patients with moderate aplastic anemia. Blood. 2003;102(10):3584-3586.

39. Sloand EM, Olnes MJ, Weinstein B, et al. Long-term follow-up of patients with moderate aplastic anemia and pure red cell aplasia treated with daclizumab. Haematologica. 2010;95(3):382-387.

40. Song Y, Li N, Liu Y, et al. Improved outcome of adults with aplastic anaemia treated with arsenic trioxide plus ciclosporin. Br J Haematol. 2013;160(2):266-269.
41. Rosenfeld SJ, Kimball J, Vining D, et al. Intensive immunosuppression with antithymocyte.

42. Rosenfeld S, Follmann D, Nunez O, et al. Antithymocyte globulin and cyclosporine for severe aplastic anemia: association between hematologic response and long-term outcome. JAMA. 2003;289(9):11301135 .

43. Saracco P, Quarello P, Lori AP, et al. Cyclosporin A response and dependence in children with acquired aplastic anaemia: a multicentre retrospective study with long-term observation follow-up. $\mathrm{Br} \mathrm{J}$ Haematol. 2007;140(2):197-205.

44. Young NS, Calado RT, Scheinberg P. Current concepts in the pathophysiology and treatment of aplastic anemia. Blood. 2006;108(8): 2509-2519.

45. Schrezenmeier H, Passweg JR, Marsh JC, et al. Worse outcome and more chronic GVHD with peripheral blood progenitor cells than bone mar- row in HLA-matched sibling donor transplants for young patients with severe acquired aplastic ane- mia. Blood. 2007;110(4):1397-1400.

46. Chu R, Brazauskas R, Kan F, et al. Comparison of outcomes after transplantation of $\mathrm{G}-\mathrm{CSF}$ - stimulated bone marrow grafts versus bone mar- row or peripheral blood grafts from HLA-matched sibling donors for patients with severe aplastic anemia. Biol Blood Marrow Transplant. 2011;17(7):1018-1024.

47. Eapen M, Le Rademacher J, Antin JH, et al. Ef- fect of stem cell source on outcomes after unre- lated donor transplantation in severe aplastic anemia. Blood. 2011;118(9):2618-2621.

48. Young NS, Barrett AJ. The treatment of severe acquired aplastic anemia. Blood. 1995;85:3367.

49. Davies JK, Guinan EC. An update on the management of severe idiopathic aplastic anaemia in children. Br J Haematol. 2007;136(4): 549-564.

50. Scheinberg P, Young NS. How I treat acquired aplastic anemia. Blood. 2012;120(6):1185-1196.

51. Tichelli A, Marsh JC. Treatment of aplastic anemia in elderly patients aged $>60$ years. Bone Marrow Transplant 48: 180 .

52. Young NS (2000) Aplastic anaemia. The Lancet. 2013;346(8969):228232

53. Höchsmann B, Moicean A, Risitano A, et al. Supportive care in severe and very severe aplastic anemia. Bone Marrow Transplant. 2013;48(2):168-173. 